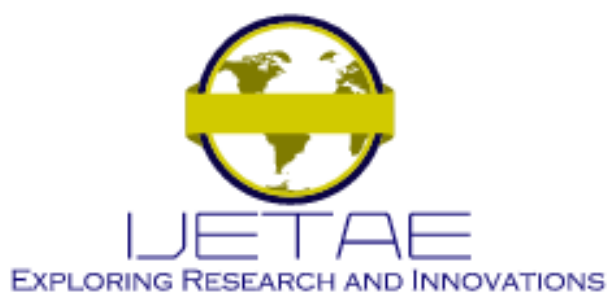

International Journal of Emerging Technology and Advanced Engineering

Website: www.ijetae.com (E-ISSN 2250-2459, Scopus Indexed, ISO 9001:2008 Certified Journal, Volume 11, Issue 10, October 2021)

Manuscript Received: 04 September 2021, Received in Revised form: 03 October 2021, Accepted: 14 October 2021

DOI: $10.46338 /$ ijetae1021_13

\title{
Implementation of Differential Sensing Scheme to Remove Panel Noise in Touchscreen Controller
}

\author{
Giao N. Pham ${ }^{1}$, Binh A. Nguyen ${ }^{2}$ \\ ${ }^{I}$ Dept. of Computing Fundamentals, ${ }^{2}$ ICT Department, FPT University, Hanoi, Vietnam
}

\begin{abstract}
Differential sensing scheme is an improvement method from single-line sensing to cancel display or panel noise in touchscreen system. However, differential sensing method raised a multiple-touches cancelation issue. As a consequence, the recovery algorithm is invented to overcome those issues. This paper introduces several methods to implement differential sensing scheme with recovery algorithm to remove panel noise and white noise in touchscreen system.
\end{abstract}

Keywords-- Digital system design, System on chip, ASIC digital design, Capacitive touch sensing.

\section{INTRODUCTION}

Nowadays, we can find many applications of touchscreen panels in industrial and consumer electronics such as smartphone, car, computer, electronic voting machines, point of sale system, personal digital assistance, ATM, keyboard, mouse,.. [1] The basic architecture of a touchscreen system includes the driving signal parts, the sensing part, the analogue-digital-converter, a Microcontroller Unit for calculation of touch-point, noise canclation [2].

Among many possible architectures of a touchscreen system, the capacitance sensor touchscreen is popularly used since its advantage [3-5]. In capacitance sensing, sigle line sensing is the most basic sensing scheme. To improve and overcome the issues in single line sensing, differential sensing schems is proposed for the panel noise cancelation [6-8]. In this article, we will discuss the several methods for implementation of differential sensing scheme with in touchscreen system. The organization of this article is as follows. In the section 2, we discuss the capacitance sensing concepts, the architecture of differential sensing scheme. Section 3 will explain the implementation of the differential sensing with via ASIC hardware and firmware (MCU).

\section{Differential Sensing Scheme}

\section{A. Capacitance Touchscreen and Sensing Schemes}

FIGURE I shows two touchscreen architectures using single-line and differential sensing schemes. They differ to each other by the sensing switches and the analogues parts (integrator vs differential amplifier and differential integrator).

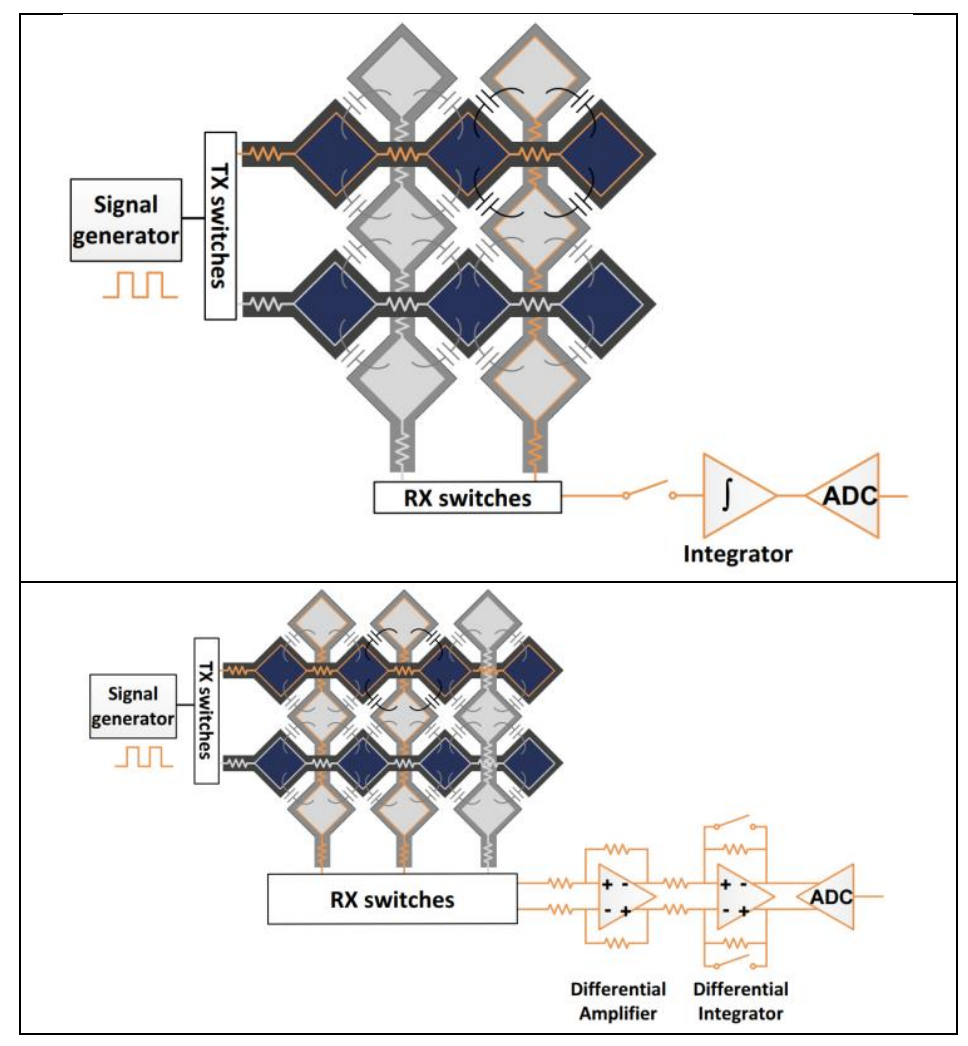

Figure I. Sensing Schemes in Capacitance Touchscreen 


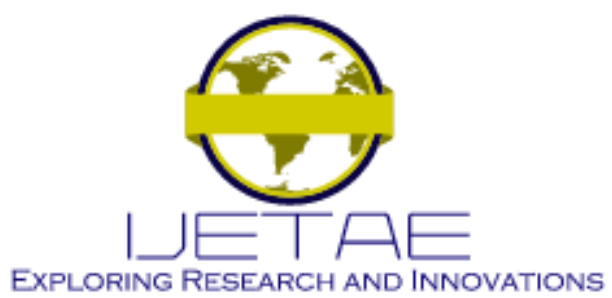

International Journal of Emerging Technology and Advanced Engineering

Website: www.ijetae.com (E-ISSN 2250-2459, Scopus Indexed, ISO 9001:2008 Certified Journal, Volume 11, Issue 10, October 2021)

\section{B. Recovery Algorithm for Differential Sensing Scheme}

To improve the effective of touchscreen system, instead of using single-line sensing, we consider the method of differential sensing (DS). The algorithm of DS can be seen in FIGURE II. As the influence of threshold, we can cancel the display or white noise.

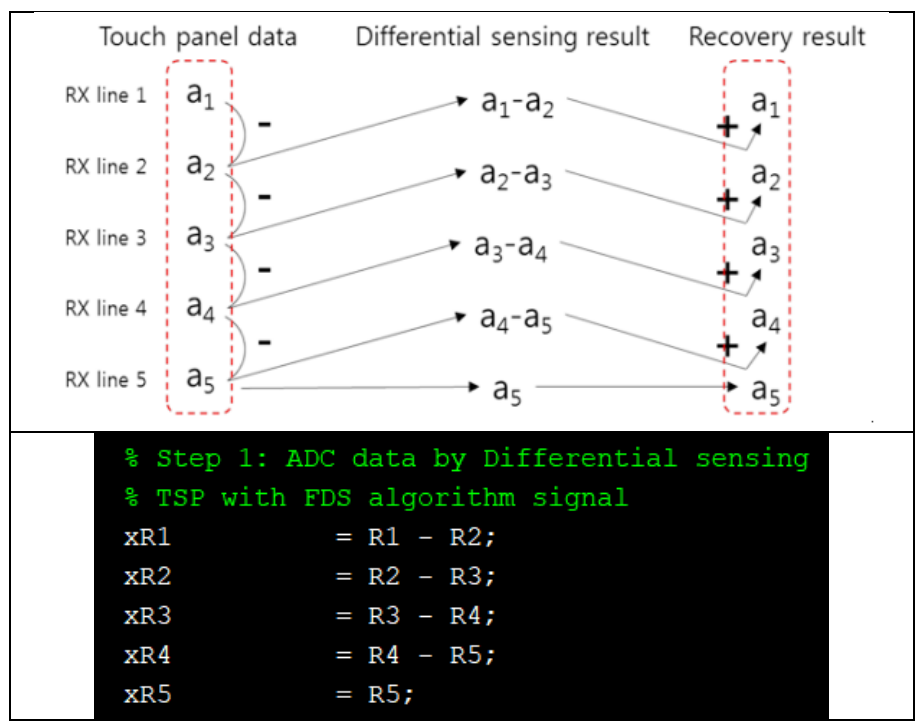

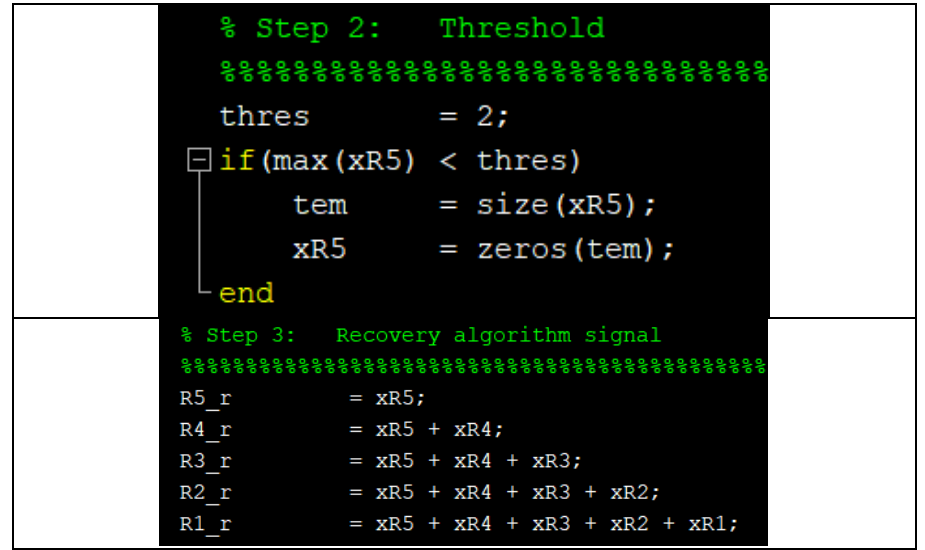

Figure II. Recovery Algorithm For Ds Scheme

\section{PRoposed Methods To IMPLEMENT DS WITH RECOVERY ALGORITHM}

In touchscreen system, the analogue signal will go into the ADC module for data digital conversion. Then, it is converted into ADC data. After that, we will extract the frequency power by FFT module.

With DS scheme, we can have three methods for implementation of recovery algorithm as FIGURE III part 1 , part 2, and part 3 . The simulation results are attached together for each method. As the consequence, we can implement Recovery algorithm as hardware module (as figure 3.1 or figure 3.2 , and it can be implemented by firmware as figure 3.3 . 


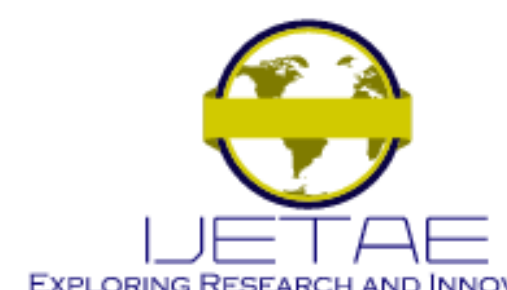

EXPLORING RESEARCH AND INNOVATIONS

International Journal of Emerging Technology and Advanced Engineering

Website: www.ijetae.com (E-ISSN 2250-2459, Scopus Indexed, ISO 9001:2008 Certified Journal, Volume 11, Issue 10, October 2021)

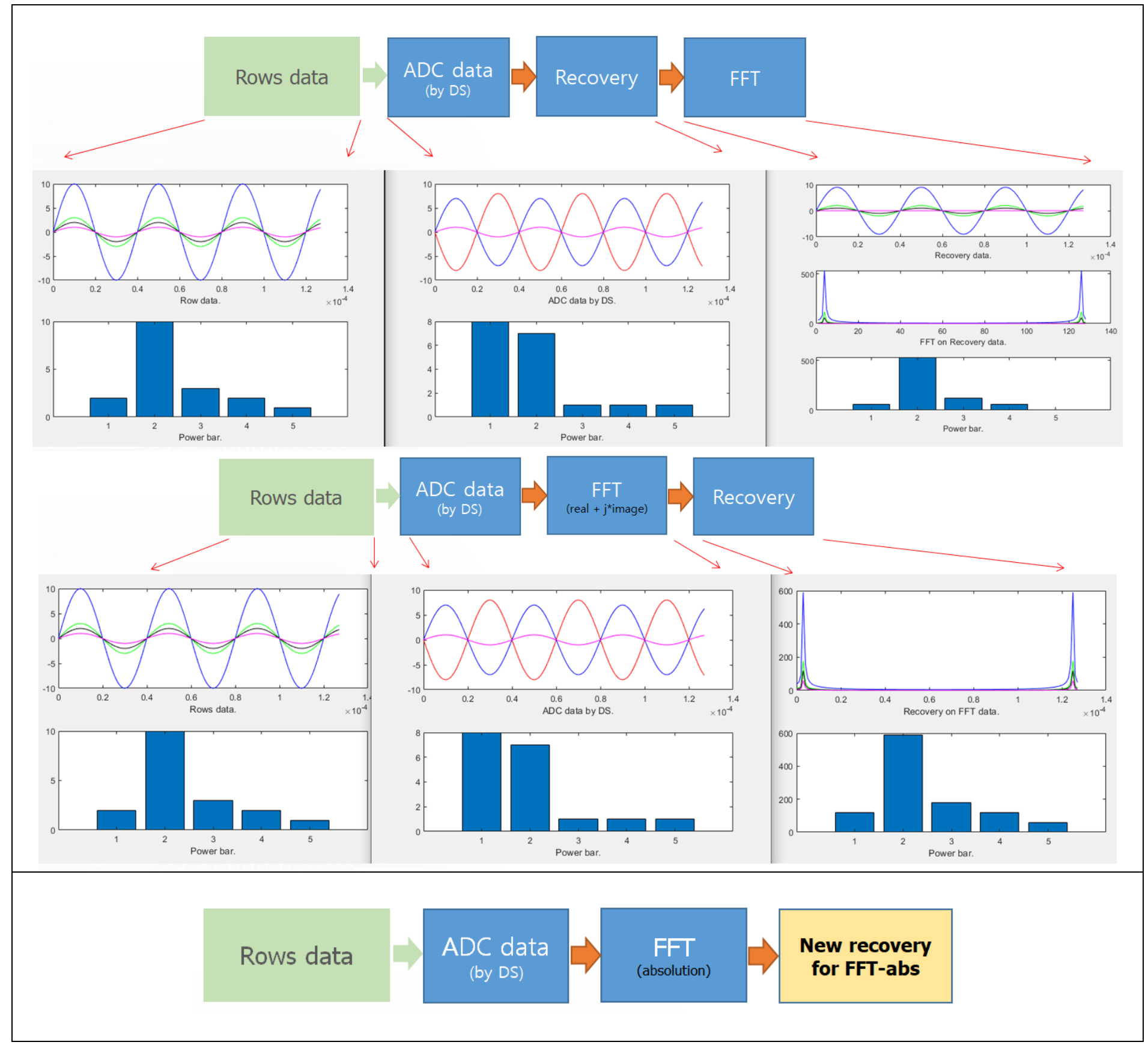




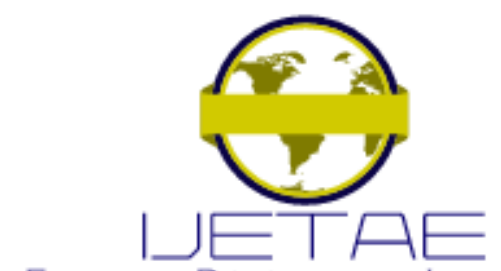

EXPLORING RESEARCH AND INNOVATIONS

International Journal of Emerging Technology and Advanced Engineering

Website: www.ijetae.com (E-ISSN 2250-2459, Scopus Indexed, ISO 9001:2008 Certified Journal, Volume 11, Issue 10, October 2021)

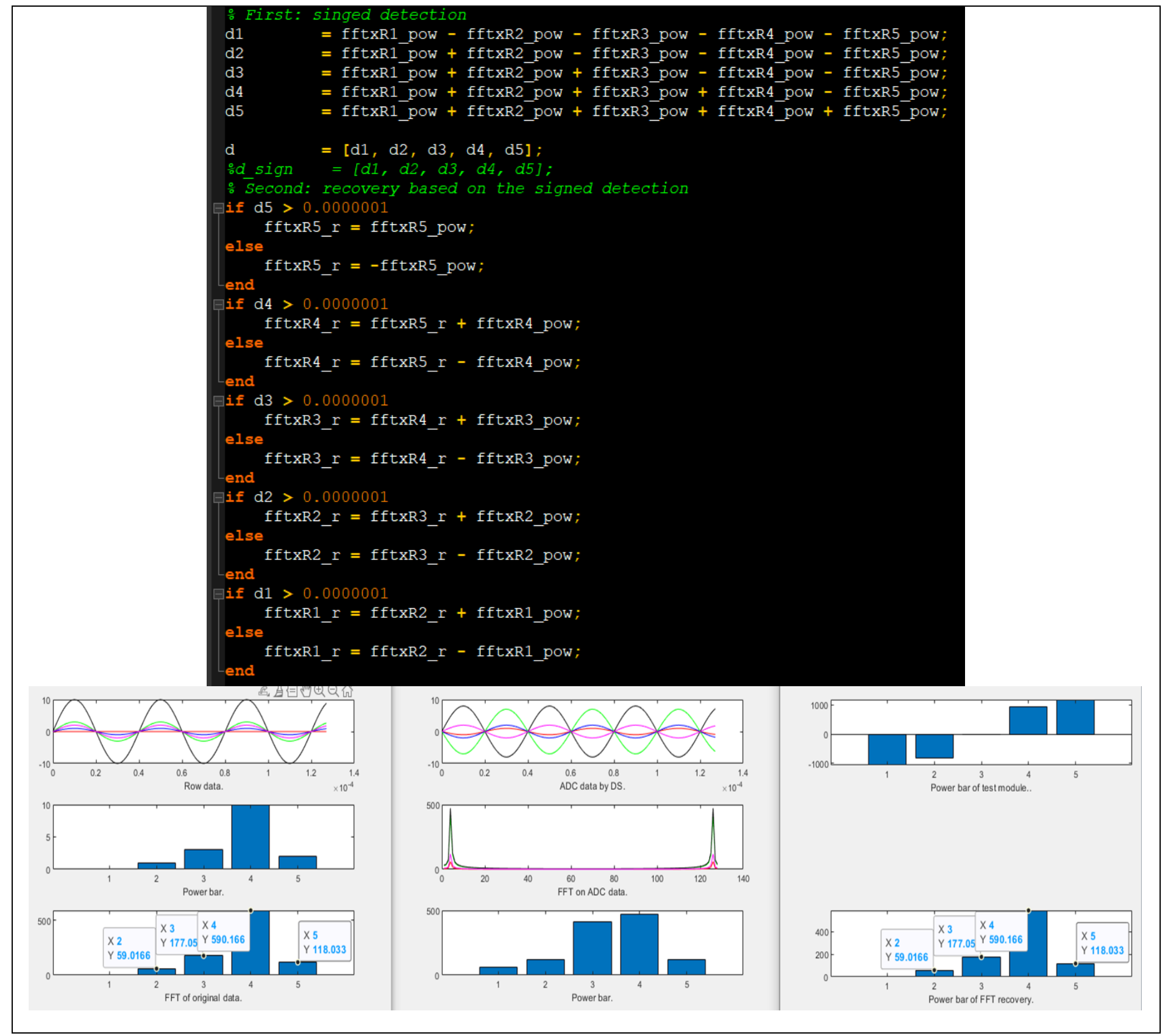

Figure III: Scenarios To Apply DS Into Touchscreen System. 


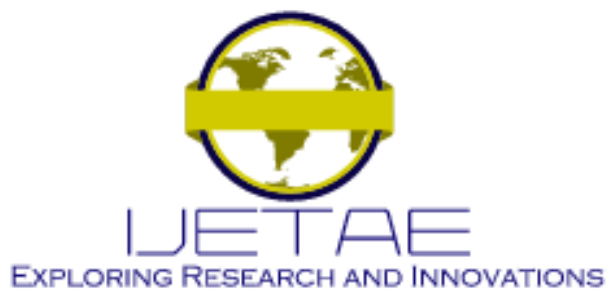

International Journal of Emerging Technology and Advanced Engineering

Website: www.ijetae.com (E-ISSN 2250-2459, Scopus Indexed, ISO 9001:2008 Certified Journal, Volume 11, Issue 10, October 2021)

\section{CONCLUSION}

In this paper, three methods for implementation of recovery algorithm for DS scheme in the touchscreen system are discussed. As the consequence, we can implement it as hardware module or by software (in firmware). Author hopes that it will be a good reference for researchers and engineers in digital system design for touchscreen system.

\section{Acknowledgement}

This work is supported by FPT University, Hanoi, Vietnam

\section{REFERENCES}

[1] N. K. Mada and H. Jagadish, "Waking up a capacitive touch sensing device with an MCU peripheral," 2021 [Internet], Available: http://www.embedded.com/design/mcus-processorsandsocs/4218309/Waking-up-a-capacitive-touch-sensing-devicewith-anMCU-peripheral

[2] J. H. Kim. et. al. Touch position recovery algorithm for differential sensing touch screen. J. Inf. Commun. Converg. Eng. 14 (2), 106114, 2016.
[3] C. L. Lin, Y. M. Chang, H. S. Chen, C. Y. Chuang, and T. C. Chu, "Position tracking based on particle filter for self-capacitance singletouch screen panels," Journal of Display Technology, vol. 11, no. 2, pp. 165-169, 2015.

[4] P. Y. Li and Z. W. Li, "Study on calibration algorithm of embedded touch screen," Journal of Multimedia, vol. 9, no. 4, pp. 605-610, 2014

[5] Nguyen, D. M. et. al. "A novel construction for quantum stabilizer codes based on binary formalism". International Journal of Modern Physics B 34 (8), 2050059, 2020.

[6] Giao, N. P. et. al. "Palm rejection algorithms on touch screen communication system". World Journal of Advanced Engineering Technology and Sciences 2021, 02(02), 052-057

[7] I. Seo and H. Kim, "Dual sensing with voltage shifting scheme for high sensitivity touch screen detection," Journal of the Institute of Electronics and Information Engineers, vol. 52, no. 4, pp. 71-79, 2015

[8] C. L. Lin, Y. M. Chang, C. C. Hung, C. D. Tu, and C. Y. Chuang, "Position estimation and smooth tracking with a fuzzy-logic-based adaptive strong tracking kalman filter for capacitive touch panels," IEEE Transactions on Industrial Electronics, vol. 62, no. 8, pp. 5097 $5108,2015$. 